\title{
ATP Modulation of Excitatory Synapses onto Interneurons
}

\author{
Baljit S. Khakh, ${ }^{1}$ Daniel Gittermann, ${ }^{1}$ Debra A. Cockayne, ${ }^{2}$ and Alison Jones ${ }^{1}$ \\ ${ }^{1}$ Medical Research Council Laboratory of Molecular Biology, Cambridge CB2 2QH, United Kingdom, and ${ }^{2}$ Roche Bioscience, Palo Alto, California 94304
}

\begin{abstract}
Inhibitory interneurons play important roles in neuronal circuits, but the synaptic mechanisms that regulate excitatory input onto interneurons remain to be fully understood. We show that ATP-gated presynaptic P2X2 channels facilitate excitatory transmission onto stratum radiatum interneurons but not onto CA1 pyramidal neurons. ATP released endogenously during carbachol-induced oscillations facilitates excitatory synapses onto interneurons. Overall, these data provide evidence for the molecular identity, synaptic function, and interneuron synapse specificity of a presynaptic neurotransmitter-gated cation channel. The findings highlight a novel form of presynaptic facilitation for hippocampal interneurons and suggest a role for extracellular ATP in neuronal networks.
\end{abstract}

Key words: ATP; P2X; synapse; interneuron; channel; oscillation

\section{Introduction}

Inhibitory interneurons form extensive GABAergic and electrical synapses among themselves and GABAergic synapses onto pyramidal neurons (McBain and Fisahn, 2001). By virtue of their precise projection patterns, distinct interneurons set a time window for when pyramidal neurons cannot spike (McBain and Fisahn, 2001). Interneurons shape the ability of the hippocampus to process information because they modulate and contribute to neuronal network oscillations in distinct frequency bands in the hippocampus both in vivo and in vitro (Buzsaki, 2002). Theta $(4-12 \mathrm{~Hz})$ oscillations are absent during immobility, occur during states of locomotor activity, and are present during rapid eye movement sleep, whereas gamma $(\sim 30-80 \mathrm{~Hz})$ oscillations occur during states of arousal, focused attention, and the dreaming phase of sleep and disappear during slow-wave sleep and anesthesia (McBain and Fisahn, 2001). A key task is to understand the processes that regulate excitatory input onto interneurons because they play a key role in determining oscillatory activity. In this report, we show that ATP facilitates excitatory synapses onto interneurons during oscillations.

A role for ATP as a neurotransmitter was suggested 30 years ago (Burnstock, 1972). There is accumulating evidence that extracellular ATP is both a transmitter and a modulator in the nervous system (Khakh, 2001; North, 2002). Cell surface ATPgated P2X channels have marked $\mathrm{Ca}^{2+}$ permeability and constitute a relatively new family distinct from channels for the more often studied neurotransmitters $\mathrm{ACh}$, serotonin, glutamate, GABA, and glycine. Seven mammalian P2X subunits are known (P2X1-P2X7), and at least 11 distinct channels can be assembled in pair-wise comparisons (Torres et al., 1999). Multiple P2X sub-

Received April 28, 2003; revised June 6, 2003; accepted June 11, 2003.

This work was supported by the Medical Research Council (United Kingdom) and the European Molecular Biology Organization Young Investigator Program. We thank Dr. Bazbeck Davletov and Colin Rickman for use of equipment and guidance with the firefly luciferase experiments; James Fisher, Nigel Unwin, Terrance Egan, and Rosalie Uchanski for comments and discussions; and Prof. John Jefferys, Prof. Paul Tiesinga, and Prof. Jean-Marc Fellous for comments on aspects of this work.

Correspondence should be addressed to Baljit S. Khakh, Medical Research Council Laboratory of Molecular Biology, Hills Road, Cambridge CB2 2QH, UK. E-mail: bsk@mrc-Imb.cam.ac.uk.

Copyright $\odot 2003$ Society for Neuroscience $\quad$ 0270-6474/03/237426-12\$15.00/0 units reside in postsynaptic and presynaptic membranes in the brain (MacDermott et al., 1999; Khakh, 2001), and the possibility that ATP has a widespread role in brain synapses is enticing because ATP is found in the cytosol of cells (Hinkle and McCarty, 1978), is released in an activity-dependent way (Zimmermann, 1994), mediates an excitatory synaptic current in some neurons (North, 2002), and is degraded in the extracellular space by specific enzymes (Zimmermann and Braun, 1996). P2X channels are widely expressed in the hippocampus (Kidd et al., 1995; Collo et al., 1996; Kanjhan et al., 1999; Rubio and Soto, 2001), but the physiology of ATP signaling at interneuron synapses has remained unexplored.

In this study, we sought to understand the physiological role of P2X channels in hippocampal CA3 neurons. We found no evidence for functional P2X responses in CA3 pyramidal neuron somata from freshly isolated mouse brain slices. We found evidence for functional P2X channels in the axons of CA3 neurons branching to their postsynaptic targets and predominantly in nerve terminals forming synapses onto interneurons. Pharmacological experiments suggested a role for P2X2, and we verified this by studying P2X2 null mice. P2X2 channel expression in nerve terminals was specific for interneuron synapses. Finally, our data indicate that nerve terminal P2X channels at interneuron synapses are activated by endogenous ATP released during theta frequency network oscillations. Collectively, these data provide evidence for a hitherto unappreciated synaptic mechanism at excitatory synapses onto interneurons.

\section{Materials and Methods}

Physiology. Young (10- to 15-d-old) C57 mice were killed in accord with home office and local procedures, and a model 1000 Plus Vibratome was used to prepare 250 - to $300-\mu \mathrm{m}$-thick coronal slices of hippocampus (Frazier et al., 1998). During incubation the slices were submerged at room temperature in artificial CSF comprising (in mM): $124 \mathrm{NaCl}, 3.3$ $\mathrm{KCl}, 2.4 \mathrm{MgSO}_{4}, 10$ D-glucose, $2.5 \mathrm{CaCl}_{2}, 1.2 \mathrm{KH}_{2} \mathrm{PO}_{4}$, and $25.9 \mathrm{NaHCO}_{3}$ saturated with $95 \% \mathrm{O}_{2}$ and $5 \% \mathrm{CO}_{2}$ gas. All experiments were performed at room temperature while the tissue was superfused with artificial CSF (aCSF) at a rate of $2 \mathrm{ml} / \mathrm{min}$. Whole-cell patch-clamp recording was accomplished by using glass pipettes pulled using a Flaming-Brown electrode puller (Sutter Instruments, Novato, CA). The resistance of the 
pipettes was $\sim 5 \mathrm{M} \Omega$ when filled with a potassium gluconate-based internal solution, which comprised (in $\mathrm{mM}$ ): $130 \mathrm{~K}$ gluconate (or $\mathrm{KCl}$ ), 1 EGTA, $2 \mathrm{MgCl}_{2}, 0.5 \mathrm{CaCl}_{2}$, and $10 \mathrm{HEPES}$, pH 7.25. Cells were visualized with infrared optics [Luigs \& Neumann or Olympus Optical (Tokyo, Japan); $900 \mathrm{~nm}$ infrared-differential interference contrast (IR-DIC)] on an upright microscope (Olympus BX50 or BX51). The ATP puff was imaged with $10 \mu \mathrm{M}$ adenosine $5^{\prime}$ triphosphate, BODIPY FL $2^{\prime}$-(or- $\left.3^{\prime}\right)$ $\mathrm{O}$-(N-(2-amino ethyl) urethane), trisodium salt (BODIPY-ATP; Molecular Probes, Eugene, OR) as a tracer on a setup using a monochromator, cooled Imago CCD camera, and Vision software (TiLL Photonics). Puffs of ATP were applied under visual control using a Picospritzer II (General Valve, Fairfield, NJ). In all cases, we puffed P2X agonists for 50, 500, and $5000 \mathrm{msec}$ to each cell and then in some cases removed the puffer pipette and repositioned another containing glutamate onto the same neuron and confirmed that the cells were responsive to glutamate; all cells responded to glutamate. Use of the adenosine receptor antagonist cyclopentyl-1,3-dipropylxanthine (10-100 $\mu \mathrm{M})$ in the bathing medium ruled out P1 receptor involvement. Inward currents were recorded at $-60 \mathrm{mV}$ using pCLAMP 8 software, an Axoclamp 1D amplifier, and Digidata 1322 (Axon Instruments, Foster City, CA). Interneurons within the CA1 region are extremely diverse (Freund and Buzsaki, 1996). In a specific set of experiments, we attempted to relate firing patterns (regular, irregular, and clustered) to the presence of $\mathrm{P} 2 \mathrm{X}$-mediated facilitation, because only $\sim 60 \%$ of interneurons responded to ATP and adenosine $5^{\prime}-O$-(thiotriphosphate) (ATP $\left.\gamma \mathrm{S}\right)$ with a change in excitatory synaptic transmission. Because we found no correlation, we suggest that the $\sim 60 \%$ of interneurons that receive ATP-modulated synapses are from a cross section of neurons that populate the stratum radiatum and cannot be classified into a distinct class based on firing properties. This said, the majority of interneurons in the stratum radiatum fired regularly (Freund and Buzsaki, 1996). Antidromic action currents and evoked EPSCs were evoked with the aid of a Grass S48 stimulator. For the experiments on antidromic action currents, the monopolar glass stimulating electrode was placed in the Schaffer collaterals, and voltage-clamp recordings were made from CA3 pyramidal neurons with all synaptic transmission blocked (Semyanov and Kullmann, 2001).

Cultured hippocampal neurons were prepared and infected as described (Khakh et al., 2001). For measurements of ATP release, we collected five $20 \mu \mathrm{l}$ samples every $5 \mathrm{~min}$ from the bathing medium $(3 \mathrm{ml}$, see above for constituents, bubbled with $95 \% \mathrm{O}_{2}$ and $5 \% \mathrm{CO}_{2}$ ) surrounding the brain slices in a scintillation vial. $\mathrm{KCl}$, TTX, or muscarine was directly added to the bathing medium after two or three control samples were collected. The $20 \mu \mathrm{l}$ samples were assayed for their ability to promote ATP-dependent bioluminescence using the firefly luciferase assay (Sigma, Poole, UK) according to the manufacturer's instructions.

Field recordings were obtained under conditions nearly identical to those used for the whole-cell recordings to make comparisons possible. The recording electrode (filled with ACSF) was placed in the CA3 cell body area approximately halfway into the slice. We performed these experiments with submerged slices with the aid of a $10 \times$ objective and adjusted the bath volume to ensure that the slices were submerged under a thin film of extracellular buffer ( $<0.5 \mathrm{~mm}$ in depth), which flowed over the slices. Extracellular oscillations were measured with an Axoclamp 2A amplifier and pCLAMP8 software.

All chemicals used were from Tocris (Bristol, UK) or Sigma. In the text, the names of the chemicals abbreviated are pyridoxal-phosphate-6azophenyl-2',4'-disulfonic acid (PPADS), carbamylcholine chloride (CCh), 6-cyano-2,3-dihydroxy-7-nitroquinoxaline (CNQX), neomycin (Neo), and L-(+)-2-amino-4-phosphonobutyric acid (L-AP-4).

Molecular biology. The embryonic stem cell work and generation of the $\mathrm{P} 2 \mathrm{X} 2^{-1-}$ mice were performed using routine methods (Hogan et al., 1994), and a preliminary report was published previously in abstract form (Cockayne et al., 2002). Briefly, exons 2-11 were deleted and replaced by a neomycin resistance cassette by homologous recombination in 129Ola-derived E14-1 embryonic stem cells (see Fig. 6). The remaining exon 1 is insufficient to form a functional protein (Khakh, 2001; North, 2002). The targeted clones were injected into C57BL/6 blastocysts; chimeras were established; and germ line transmission of the targeted allele was established by mating chimeras to $\mathrm{C} 57 \mathrm{BL} / 6$ mice. All mice analyzed in this study have the genetic background 1290la $\times$ C57BL/6 (The Jackson Laboratory, Bar Harbor, ME) and were derived from homozygous wild-type and $\mathrm{P} 2 \mathrm{X} 2^{-1-}$ breeders. There were no obvious behavioral or developmental deficits with the $\mathrm{P} 2 \mathrm{X} 2^{-1-}$ homozygous mice. PCR screening of tail genomic DNA was performed using Extaq (Panvera): the sense primer in exon 1 was $5^{\prime}$-GTG CAG CTG CTC ATT CTG CTT-3'; the exon 2 antisense primer was $5^{\prime}$-CTG CAC GAT GAA GAC GTA CCT- $3^{\prime}$; and the Neo antisense primer was 5' -ACG AGT TCT TCT GAG GGG ATC GGC-3'. We isolated mRNA from whole brain and testis with oligo-dT beads using the Quick Prep Micro mRNA purification kit (Amersham Biosciences, Arlington Heights, IL). cDNA was reverse-transcribed from mRNA using Moloney murine leukemia virus reverse transcriptase and oligo-dT primers (Advantage reverse transcriptase for PCR kit; Clontech, Palo Alto, CA), and PCR was performed using Taq polymerase (TaqPCR core kit; Qiagen, Hilden, Germany). We used rat $\beta$-actin primers as controls [reverse transcription (RT)-PCR amplimers; Clontech] and the following primers for the P2X2 gene: sense, 5'-ACG TTC ATG AAC AAA AAC AAG-3'; and antisense, 5'-TCA AAG TTG GGC CAA ACC TTT GG-3'. These primers are in exon 11 and amplify 358 bp of sequence corresponding to the P2X2 C-terminal domain.

Analysis. Synaptic currents were analyzed using MiniAnalysis program 5.3.5 (Synaptosoft) and Origin 5.1 (Origin Lab Corp.). In the analysis of miniature EPSCs (mEPSCs) and spontaneous EPSCs (sEPSCs), we designated a particular neuron as a responder or nonresponder post hoc, after analyzing all events with MiniAnalysis. Thus, responders were deemed as such if they showed a reversible increase in frequency of events concomitant with the agonist application (from frequency vs time plots). The frequency of events varied from cell to cell; in most cases responders were very clear, but neurons showing less than a doubling of the frequency could have been classified as nonresponders. Data in the text and graphs are shown as mean \pm SEM from $n$ determinations as indicated. All experiments comparing $\mathrm{P} 2 \mathrm{X} 2^{+/+}$and $\mathrm{P} 2 \mathrm{X} 2^{-1-}$ mice were performed blind. Fast Fourier transforms were performed on $20 \mathrm{sec}$ segments of data within Clampfit 8.0 (Axon Instruments) or Origin, and the peak power as shown in the figures was determined between 3 and $20 \mathrm{~Hz}$. Paired pulse facilitation was calculated as the ratio of the means of the second response to the mean of the first from 20 individual sweeps for each cell.

\section{Results}

We first present data to show that P2X channels are functionally absent from CA3 somata but are functionally present in axons and nerve terminals emanating from CA3 neurons and forming synapses onto interneurons. We next provide insight as to how $\mathrm{P} 2 \mathrm{X}$ channels facilitate transmitter release from these nerve terminals and into the molecular composition of the channels. Finally, we provide evidence for how nerve terminal P2X channels may be activated during network activity.

Little evidence for P2X channels in intact CA3 neuron somata Of the seven known P2X subunits, P2X2, P2X4, and P2X6 are found in hippocampal CA3 neurons (Collo et al., 1996; Kanjhan et al., 1999; Rubio and Soto, 2001). We performed patch-clamp recordings from neurons in freshly isolated hippocampal slices and rapidly puffed ATP to measure P2X responses in CA3 neurons. Brief puffs of ATP (0.1-1 mM), and the more stable ATP analog ATP $\gamma \mathrm{S}(100 \mu \mathrm{M})$ failed to evoke inward currents in CA3 neuron somata (Fig. 1A, $i$; Table 1 ), whereas we could readily measure fast glutamate-evoked currents from these cells. This was surprising because a recent study reported ATP-evoked currents with rise times approaching $\sim 300 \mathrm{msec}$ in five CA3 neurons (Mori et al., 2001). Methodological differences offer a straightforward explanation for the discrepancies between our data from freshly isolated mouse slices and those using immature rat organotypic slices maintained in culture for 2-4 weeks. In accord, 
larger P2X responses have been noted in sensory neurons after culturing compared with responses from freshly isolated ganglia (North, 2002).

ATP was also ineffective at evoking inward currents in other, but not all, types of hippocampal neurons (Fig. 1A, ii-iv; Table 1 ). In contrast, glutamate evoked responses in all hippocampal neurons (Fig. $1 A, i-i v$; Table 1). High concentrations of ATP (3 mM) evoked large inward currents in interneurons (Table 1), but these are artifacts because the $\mathrm{pH}$ of $3 \mathrm{~mm}$ ATP is 5.5, and adjusting the $\mathrm{pH}$ to 7.4 renders $3 \mathrm{~mm}$ ATP ineffective (Table 1). In contrast to the lack of somatic ATP-evoked currents in CA3 neurons, we could measure ATPevoked currents in stratum oriens interneurons (Fig. 1A, iv; Table 1) and brainstem trigeminal mesencephalic nucleus $\mathrm{V}$ neurons (Khakh et al., 1997) when ATP was similarly applied $(-54 \pm 10 \mathrm{pA} ; n=$ $6)$, as well as rapidly desensitizing AChevoked currents $(-95 \pm 9.6 \mathrm{pA} ; n=6$ of 9 neurons) in stratum radiatum (SR) interneurons (Frazier et al., 1998). The ATPevoked currents in stratum oriens interneurons displayed $10-90 \%$ rise times of $508 \pm 112 \operatorname{msec}(n=6)$, whereas glutamate-evoked currents reached peak responses with rise times of $<20 \mathrm{msec}$ ( $\mathrm{Ta}$ ble 1). We did not study the ATP-evoked current in stratum oriens interneurons further in this study. These data indicate that P2X channels are not expressed at functionally detectable levels in CA3 neuron somata.

\section{ATP acting on P2X channels increases sEPSC frequency onto interneurons}

The majority of CA1 stratum radiatum interneurons receive their predominant glutamatergic input from CA3 neuron Schaffer collaterals (Gulyas et al., 1999). This population of interneurons likely innervates CA1 pyramidal neurons to regulate dendritic $\mathrm{Ca}^{2+}$ entry, spiking, or both (Miles et al., 1996; Gulyas et al., 1999; McBain and Fisahn, 2001). Thus one possible explanation for the lack of functional somatic P2X channels is that the channels may be located in axons and nerve terminals away from CA3 neuron somata. We recorded glutamatergic sEPSCs from interneurons loaded with Lucifer yellow to optically mark their position (Fig. $1 B$ ) and then puffed ATP or ATP $\gamma$ S nearby to see whether P2X channels are functional in nerve terminals and axons of CA3 neurons forming synapses onto interneurons (Fig. $1 B, C$ ). Concomitant with the ATP puff, we recorded a $\sim 740 \%(n=5)$ increase in spontaneous EPSC frequency from interneurons (Fig. 1D). A puff of aCSF produced no detectable changes in the sEPSC frequency $(n=5)$, and the ATP responses were blocked $\sim 80 \%(n=5$; Fig. $1 D)$ by the slowly dissociating ATP receptor antagonist PPADS (30 $\mu \mathrm{M}$; recovery to $\sim 50 \%$ of initial with a 30 min wash; $n=4$ ), which blocks homomeric P2X2 but not P2X4 or P2X6 channels (North, 2002). We did not use the P2 receptor antagonist suramin because it blocks glutamate-gated ion channel responses (Khakh
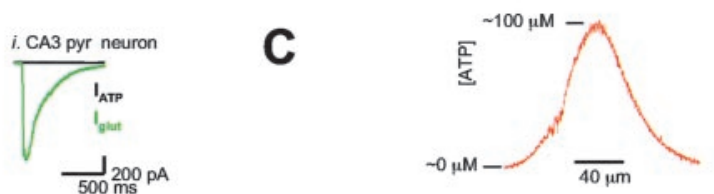

D

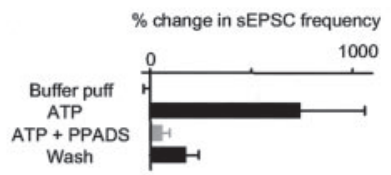

E
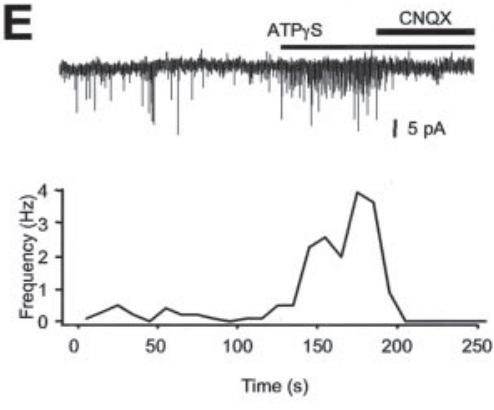

Figure 1. Functional $P 2 X$ channels are absent from CA3 somata but modulate excitatory synaptic transmission onto interneurons. A, Simplified diagrammatic representation of the hippocampus and the feedforward circuit formed between CA3 (green) and CA1 (blue) pyramidal neurons and interneurons (red). $i-i V$, The black traces are current waveforms ( $-60 \mathrm{mV}$ ) for ATP puffs 作 the puffer pipette filled with the fluorescent ATP analog BODIPY-ATP (bottom left). ATP was puffed in the third frame. The plume of ATP spreads only $\sim 160 \mu \mathrm{m}$ and is restricted to the stratum radiatum: the concentration of BODIPY-ATP beyond $\sim 160 \mu \mathrm{m}$ is a the last three frames show that ATP is efficiently washed away after the puff. The interval between frames was $5 \mathrm{sec}$ summarizing initial experiments with ATP puffs to interneurons. $E$ Top Recording ofaninterneuron holding current $(-60 \mathrm{mV})$ before and during ATP $\gamma$ S application in the bath and then with ATP $\gamma$ S and CNOX present. The bottom plot shows the frequency of EPSC recorded from the same cell plotted versus time. Note that all EPSCs are blocked when CNQX was applied.

and Henderson, 1998), whereas PPADS does not (see below). The facilitating responses were constant for agonist applications every 2-3 min, desensitized slowly (mean $\tau, 1.8 \mathrm{~min}$ ), and were not mimicked by $\alpha, \beta$-methylene-ATP (North, 2002). ATP $\gamma S$ $(100 \mu \mathrm{M})$ was as effective as ATP (1 mM; see below and Fig. $4 B$ ). We subsequently used ATP $\gamma \mathrm{S}$ because this $\mathrm{P} 2 \mathrm{X}$ agonist is more stable than ATP (Khakh et al., 1997). Of the subunits present (Collo et al., 1996; Kanjhan et al., 1999; Rubio and Soto, 2001), the data provide strong evidence for P2X2 subunit-containing channels (North, 2002) close to nerve terminals emanating from CA3 neurons. Later we present direct evidence for this.

\section{Facilitation by P2X channels is specific to synapses onto interneurons}

Interneurons and pyramidal neurons were identified on the basis of anatomical location, neuron shape, presence or lack of a thick apical dendrite, firing patterns, and decay time of sEPSCs (Fig. $2 A, B)$.

We recorded from interneurons and pyramidal neurons, both targets of CA 3 axons in the CA1 area (Freund and Buzsaki, 1996), to see whether $\mathrm{P} 2 \mathrm{X}$-mediated modulation was equivalent with bath applications of agonists. For the vast majority of CA1 pyra- 
Table 1. Little evidence for somatic fast ionotropic responses mediated by P2X channels in mouse hippocampal neurons

\begin{tabular}{|c|c|c|c|c|c|}
\hline \multirow[b]{2}{*}{ Neurons } & \multicolumn{2}{|l|}{$I_{\text {glut }}$} & \multicolumn{3}{|l|}{$I_{\text {ATP }}$} \\
\hline & $-p A$ & $n$ & Concentration & $-p A$ & $n$ \\
\hline \multirow[t]{4}{*}{ SR interneurons } & $268 \pm 21$ & 6 & $100 \mu \mathrm{M}$ ATP & $2.5 \pm 2.5$ & 6 \\
\hline & & & $100 \mu \mathrm{M}$ ATP $\gamma \mathrm{S}$ & $0 \pm 0$ & 7 \\
\hline & & & 3 mм ATP (pH 5.5) & $869 \pm 130$ & 4 \\
\hline & & & 3 mм ATP (pH 7.4) & $9.5 \pm 6.2$ & 4 \\
\hline \multirow[t]{2}{*}{ CA3 pyramidal neurons } & $1312 \pm 138$ & 10 & $100 \mu \mathrm{M} \mathrm{ATP}$ & $0 \pm 0$ & 8 \\
\hline & & & $100 \mu \mathrm{M}$ ATP $\gamma \varsigma$ & $0 \pm 0$ & 5 \\
\hline CA1 neurons & $401 \pm 93$ & 7 & $100 \mu \mathrm{M}$ ATP & $0 \pm 0$ & 9 \\
\hline SO interneurons & $1267 \pm 163$ & 3 & $100 \mu \mathrm{M}$ ATP & $189 \pm 65$ & 7 \\
\hline
\end{tabular}

Glutamate puffs were generally 50 msec in duration, whereas ATP puffs were tested at 50,500 , and 5000 msec durations. ATP was ineffective for all these durations except at $S 0$ interneurons, where $I_{\text {ATP }}$ displayed a $10-90 \%$ rise time of $508 \pm 112 \mathrm{msec}$; hence, for these neurons, we measured peak $I_{\text {ATP }}$ for $5000 \mathrm{msec}$ puffs, and for comparison we also puffed glutamate for the same duration (see Fig. $\left.1 A\right)$. We measured solution exchange kinetics at $4-20 \mathrm{msec}$ by measuring the change in tip potential on puffing low-ionic strength solution. Moreover, in initial experiments, I glut rose with a $10-90 \%$ rise time of $17.5 \pm 3.4$ msec, and the peak amplitude was constant for puffs of 50 and 5000 msec ( $11.7 \pm 10.1 \%$ change), suggesting that the neurons were "concentration-clamped" in a time frame approaching $\sim 17 \mathrm{msec}$ on average. The pH of a $3 \mathrm{~mm}$ ATP solution in aCSF was 5.5 and resulted in large currents; however, $3 \mathrm{~mm}$ was ineffective when the $\mathrm{pH}$ was titrated to 7.4 .

midal neurons, we detected no effect of ATP $\gamma \mathrm{S}$ on sEPSC frequency and amplitude (13 of 17 neurons); however, in 4 of 17 CA1 neurons, there was an increase in the frequency of sEPSCs by $2160 \%$ from $0.2 \pm 0.08 \mathrm{~Hz}$ and an increase in the amplitude of sEPSCs by $34.1 \pm 13.7 \%$ from $-10.3 \pm 2.8 \mathrm{pA}$ (Fig. $2 \mathrm{D}$ ). We did not study these neurons any further in this study because it is unclear whether sEPSCs are quantal in nature or result from increased axonal excitability. We next measured action potentialindependent quantal mEPSCs (MacDermott et al., 1999) in the presence of TTX. In all cases (16 of 16), for CA1 pyramidal neurons we observed no increases in mEPSC frequency or amplitude. Thus the frequency of mEPSCs was $0.4 \pm 0.2 \mathrm{~Hz}$ in control and $0.8 \pm 0.6 \mathrm{~Hz}$ in the presence of ATP $\gamma \mathrm{S}(n=16 ; p>0.05)$. In contrast, during recordings from interneurons, sEPSC $(n=9)$ and mEPSC $(n=10)$ frequency increased dramatically (Fig. $2 C, E)$. The effect of ATP $\gamma S$ on EPSCs was not affected by blocking $\mathrm{GABA}_{\mathrm{A}}$ and $\mathrm{GABA}_{\mathrm{B}}$ receptors with bicucculline $(100 \mu \mathrm{M})$ and 3-[[3,4-dichlorophenyl)methyl]amino]propyl] diethoxymethyl)phosphinic acid (CGP52432) (5 $\mu \mathrm{M})$. Similar to data with $\mathrm{ATP} \gamma \mathrm{S}$ alone (see below), the sESPC frequency increase was $1051 \pm 250 \%$ from $1.0 \pm 0.3 \mathrm{~Hz}$ when ATP $\gamma \mathrm{S}$ was applied in slices pretreated with bicucculline and CGP52432 $(n=10)$. These data suggest that P2X channel expression in nerve terminals does not occur in synapses onto pyramidal neurons, that the coupling between P2X activation and release is weak, or that presynaptic $\mathrm{P} 2 \mathrm{X}$ channel expression is so low that it is functionally undetectable at these synapses. In contrast, activation of P2X channels in excitatory nerve terminals onto interneurons increases neurotransmitter release.

\section{Concomitant increases in sEPSC frequency and decreases in evoked EPSC amplitude}

We next performed a specific set of experiments to compare the effect of P2X channel activation on sEPSCs and evoked EPSCs recorded simultaneously from interneurons. The majority of neurons (9 of 12; Fig. 3C,D) showed a robust and reversible increase in sEPSC frequency to $\sim 1000 \%$ of control from $0.4 \pm 0.1$ to $3.4 \pm 0.5 \mathrm{~Hz}$ in ATP $\gamma \mathrm{S}$, returning to $0.31 \pm 0.09 \mathrm{~Hz}$ on washout ( 3 of 12 , no response), with no significant increase in sEPSC amplitude from $-13.5 \pm 1.2 \mathrm{pA}$ in control to $-13.7 \pm 0.7 \mathrm{pA}$ $(p>0.05)$ in ATP $\gamma$ S. The time course of the increase in sEPSCs was matched by a concomitant decrease in the amplitude of evoked glutamatergic EPSCs by $41.4 \pm 4.7 \%(p<0.05)$ from $-91.6 \pm 8.6 \mathrm{pA}$. To ensure that we were indeed recording from interneurons that receive input from the Schaffer collaterals, we washed out the ATP $\gamma S$ and tested the effect of the group III mGluR agonist L-AP-4, which is expressed abundantly on Schaf- fer collateral nerve terminals onto interneurons (Shigemoto et al., 1996; Scanziani et al., 1998) (Fig. 3). In all 12 neurons, L-AP-4 decreased the sESPC frequency to $46.8 \pm 6.7 \%(p<0.05)$ of control $(0.8 \pm 0.2 \mathrm{~Hz})$, with a concomitant decrease in the amplitude of evoked EPSCs by $32.3 \pm 7.7 \%(p<0.05)$ from $-94.8 \pm 12.2 \mathrm{pA}$. In accord with previous findings, the L-AP-4 effect on evoked EPSCs and sEPSCs was partially reversible to $86.6 \pm 7.3$ and $71.3 \pm 8.7 \%$ of control values, respectively (Scanziani et al., 1998). There was no significant effect of L-AP-4 on sEPSC amplitude $(5.7 \pm 5.0 \%$ change from $-12.3 \pm 0.8 \mathrm{pA} ; p>$ $0.05)$. The finding that ATP $\gamma S$ facilitates sEPSC frequency and depresses evoked EPSC amplitude in the same interneurons in which L-AP-4 depresses synaptic transmission strongly suggests that ATP $\gamma S$ acts on Schaffer collateral nerve terminals onto interneurons (Scanziani et al., 1998).

\section{ATP activates $\mathrm{Ca}^{2+}$-permeable channels to increase release probability at interneuron synapses}

The predominant effect of P2X channel activation at interneurons was a decrease in evoked EPSCs and an increase in the frequency of sEPSCs (see above), which may reflect a combination of effects on nerve terminals, axons, or both. We next measured action potential-independent quantal mEPSCs (MacDermott et al., 1999) in the presence of TTX to see whether we could detect $\mathrm{P} 2 \mathrm{X}$ channel-mediated presynaptic responses. At interneuron synapses, in the presence of TTX $(0.5 \mu \mathrm{M} ; n=14)$ to block action potentials or in the presence of TTX and $\mathrm{Cd}^{2+}(100 \mu \mathrm{M} ; n=13)$ to block action potentials and $\mathrm{Ca}^{2+}$ channels, ATP and ATP $\gamma \mathrm{S}$ still evoked robust increases in the frequency of mEPSCs, reflected as shifts in the interevent distribution to shorter times with no change in the amplitude distributions (MacDermott et al., 1999) (Fig. 4A). However, the effect was abolished when extracellular $\mathrm{Ca}^{2+}$ was removed $(n=5$; Fig. $4 B)$, arguing against a contribution of metabotropic ATP receptors and instead suggesting that ATP likely gates $\mathrm{Ca}^{2+}$-permeable P2X channels in nerve terminals to increase the probability of vesicle fusion (MacDermott et al., 1999).

\section{Antidromic action currents onto CA3 neurons fail when P2X channels open}

One possible explanation for why evoked EPSCs decrease in amplitude at the same time as sEPSCs increase in frequency is that open axonal P2X channels may depress action potential initiation, conduction in axons, or both, whereas the concomitant opening of presynaptic channels increases quantal release. Analysis of mEPSCs strongly suggests that quantal release is increased (Fig. 4). In the case of axonal channels, one expects open channels 

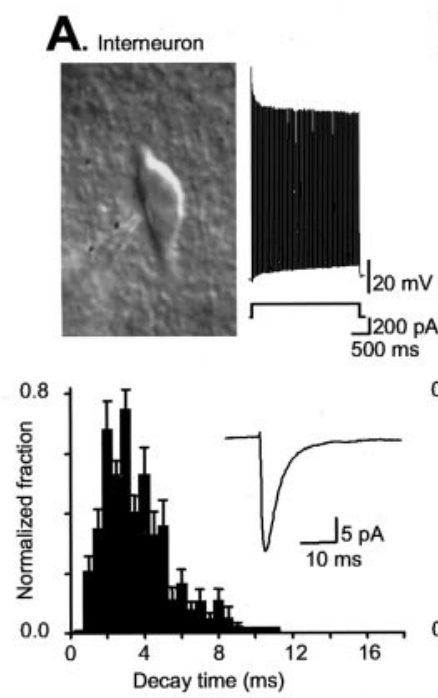

B. Pyramidal neuron
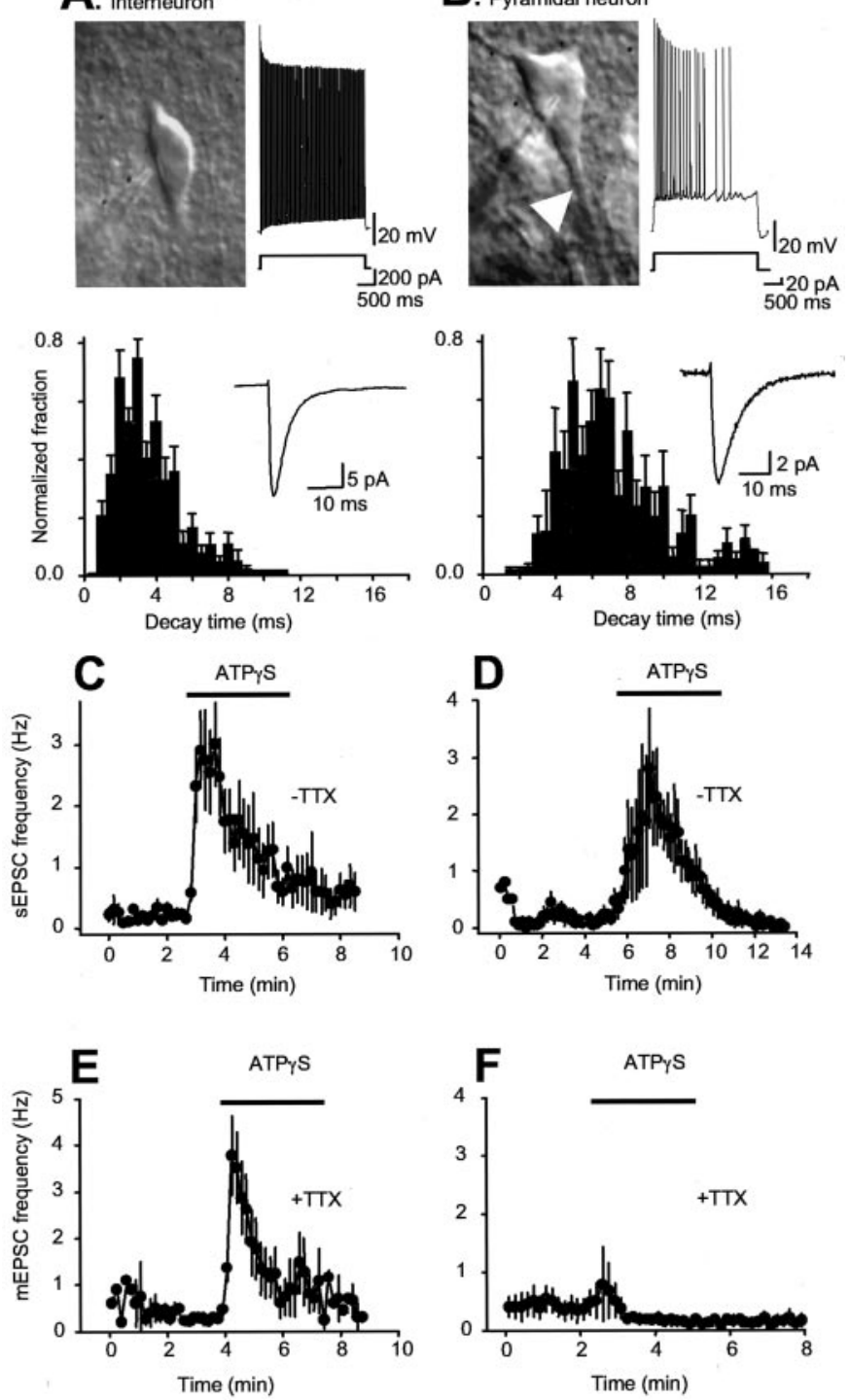

Figure 2. Interneuron-specific modulation by $P 2 X$ channels. $A$, IR-DIC image of a stratum radiatum interneuron with a patch electrode approaching from the left; note the absence of thick dendrites. The right trace is a representative voltage waveform in response to a $200 \mathrm{pA}$ depolarizing current injection. The upward deflections are action potentials, the frequencies of which are maintained throughout the step. The bottom plot shows the distribution of SEPSC decay times recorded from 13 interneurons, and the inset shows an average of $20 \mathrm{sESPC}$ from one interneuron. $B$, IR-DIC image of a CA1 pyramidal neuron with a patch electrode positioned on the soma; note the thick dendrites. The right trace is a representative voltage waveform in response to a $20 \mathrm{pA}$ depolarizing current injection. The upward deflections are action potentials, the frequency of which decreases dramatically during the step. The bottom plot shows the distribution of SEPSC decay times recorded from a CA1 pyramidal neuron, and the inset shows an average of $20 \mathrm{sESPCs}$ from one pyramidal neuron. We could readily discern interneurons from CA1 pyramidal neurons using infrared $(775-900 \mathrm{~nm})$ differential interference contrast optics on the basis of anatomical location, neuron shape, presence or lack of a thick apical dendrite, firing patterns, and decay time of sEPSCS. Pyramidal neurons accommodate on depolarizing current injection, whereas interneurons do not, and sEPSCs onto interneurons decay approximately twice as fast as those onto pyramidal neurons ( $3.4 \pm 0.2 \mathrm{msec}, 2369$ events; $n=13$; vs $7.0 \pm$ $0.4 \mathrm{msec}, 342$ events; $n=6$ ), possibly reflecting neuron-specific expression of distinct glutamate-gated channels (McBain and Fisahn, 2001). C, Interneuron data: sEPSC frequency over time before and during ATP $\gamma 5$ application $(n=9)$. D, CA1 pyramidal neuron data: sEPSC frequency over time before and during ATP $\gamma S$ application (data shown for $n=4$ of 17 neurons; the remaining 13 neurons did not respond; see Results). E, F, Time-resolved plots of mEPSC frequency for interneurons $(E ; n=10)$ and CA1 pyramidal neurons $(F ; n=16)$ before and during ATP $\gamma S$ application. ATP $\gamma S$ was applied in the bath. to increase membrane conductance and shunt action potentials both anterogradely toward the synapse and also retrogradely to the soma from which the axon originates or to depolarize axons such that sodium channels are inactivated. We performed experiments to test for this directly using an approach similar to that used recently by Semyanov and Kullmann (2001). We completely blocked synaptic transmission onto CA3 neurons using a mixture of blockers (CNQX, bicucculline, and D-2-amino-5phosphonovaleric acid, all at $100 \mu \mathrm{M}$ ) and recorded from voltageclamped CA3 neurons. Antidromic action currents were evoked with a monopolar glass-stimulating electrode placed in the Schaffer collaterals (Semyanov and Kullmann, 2001), and recorded in CA3 neuron somata at stimulus strengths resulting in $\sim 60 \%$ success rates. On application of ATP $\gamma \mathrm{S}$, we observed a significant decrease in the action current success rate for all neurons tested in this way from a mean success rate of $65.3 \pm 8.7$ to $2.5 \pm 2.9 \%$ (Fig. 5A-C; $n=9 ; p<0.05$ ). In accord with the reversible suppression of evoked EPSCs (Fig. $3 A$ ), the effect of ATP $\gamma S$ on action current success rate was also reversible to a rate of $57.1 \pm 7.1 \%$ ( $p>0.05$ compared with control). Representative traces and data from the whole sample are presented in Figure $4 A-C$. Seemingly, the predominant effect of $\mathrm{P} 2 \mathrm{X}$ channel activation in axons is to depress antidromic action currents, and this supports our hypothesis that P2X channels are expressed in the axons emanating from CA3 pyramidal neurons.

\section{The P2X2 subunit is required for ATP-evoked interneuron} synapse facilitation

P2X2 channels were the most likely molecular targets for ATP, but we sought definitive proof by using P2X2 deletion mice in which the last 10 of the $11 \mathrm{P} 2 \mathrm{X} 2$ exons have been replaced with a neomycin resistance cassette (Fig. 6A; see Materials and Methods). RT-PCR confirmed the absence of P2X2 mRNA from whole brain and testis from $\mathrm{P} 2 \mathrm{X} 2^{-1-}$ mice, whereas the expected band was obtained from $\mathrm{P} 2 \mathrm{X} 2^{+/+}$mice (Fig. $6 A$ ) and for $\beta$-actin in both genotypes (Fig. $6 \mathrm{~A}$ ). The overall anatomy of the hippocampus and spiking properties of interneurons were normal in $\mathrm{P} 2 \mathrm{X} 2^{-1-}$ mice $(n=47$ and 49 neurons from seven mice of each genotype; Fig. $6 B, C)$, and there were no differences in either resting membrane potential $(-58.9 \pm 0.8$ and $-59.6 \pm 0.9 \mathrm{mV}$; $p>0.05)$ or membrane resistance $(657 \pm 70$ and $512 \pm 45 \mathrm{M} \Omega$; $p>0.05)$ for $\mathrm{P} 2 \mathrm{X} 2^{+/+}$and $\mathrm{P} 2 \mathrm{X} 2^{-/-}$mice $(n=47$ and 49 ; Fig. $6 G, H)$. However, there was a stark difference between $\mathrm{P} 2 \mathrm{X} 2^{-1-}$ and $\mathrm{P} 2 \mathrm{X} 2^{+/+}$mice with respect to ATP $\gamma \mathrm{S}$ modulation of glutamatergic synaptic transmission onto interneurons (Fig. 6D,E,G). We recorded ATP $\gamma S$ modulation in $47 \%$ of neurons from $\mathrm{P} 2 \mathrm{X} 2^{+/+}$mice $\left(42\right.$ of 90 ), but in $\mathrm{P} 2 \mathrm{X} 2^{-1-}$ mice, this was significantly reduced to $16 \%$ (13 of 80 , seven mice for each genotype; Fig. $6, D, E$, results from individual mice, $G-I$, results from all mice). Thus, the predominant target in neurons that responded to ATP $\gamma \mathrm{S}$ with an increase in the frequency of mEPSCs is either a homomeric or heteromeric assembly comprising $\mathrm{P} 2 \mathrm{X} 2$ subunits. We next compared the absolute changes in EPSC frequency for neurons that responded to $\mathrm{ATP} \gamma \mathrm{S}$ between $\mathrm{P} 2 \mathrm{X} 2^{-1-}$ and $\mathrm{P} 2 \mathrm{X} 2^{+/+}$mice because if $\mathrm{P} 2 \mathrm{X} 2$ and putative $\mathrm{P} 2 \mathrm{X} 4 / \mathrm{P} 2 \mathrm{X} 6$ channels are expressed in the same nerve terminals, then one may expect the response magnitude to be reduced in $\mathrm{P} 2 \mathrm{X} 2^{-1-}$ mice. The absolute magnitude of the frequency change was the same (Fig. $6 F$ ), and this suggests that specificity may exist within members of the P2X family with respect to expression in nerve terminals or that ATP-gated channels are upregulated in the $\mathrm{P} 2 \mathrm{X} 2^{-1-}$ mouse line. The clearest finding from these experiments is that 


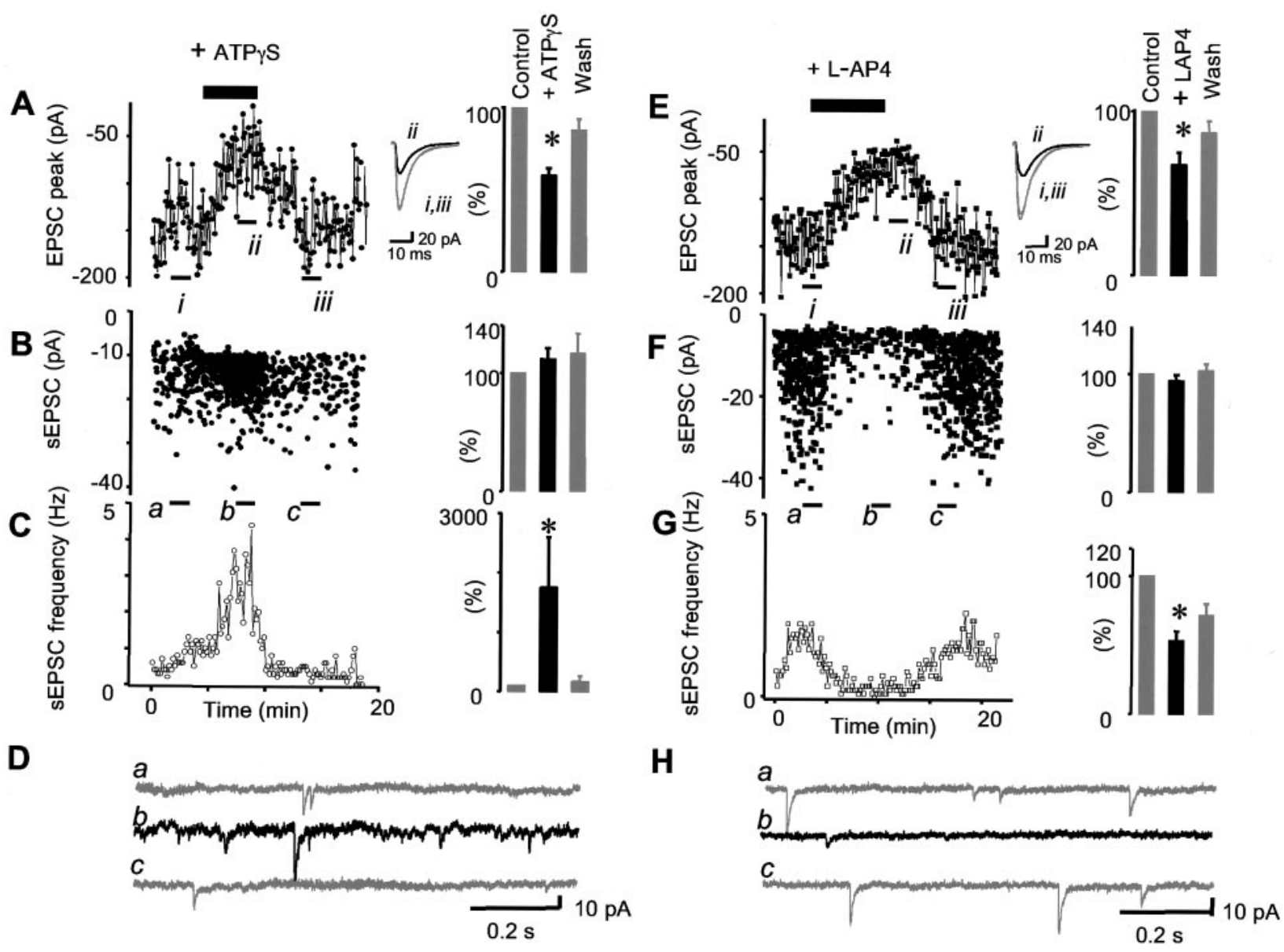

Figure 3. ATP $\gamma S$ modulation of evoked and spontaneous EPSCS at interneuron synapses. $A-D$, Data for ATP $\gamma S$ application during recordings from interneurons. $A$, Evoked EPSCs; $B$, sEPSC amplitude; C, SEPSC frequency recorded simultaneously before, during, and after ATP $\gamma S$ application for one representative neuron. D, Representative sEPSCS. A, Inset, Representative evoked EPSCS. In each case, the bar graphs to the right show average data from all experiments of this type. In all these cases, after washing out ATP $\gamma 5(\sim 10-20$ min), we applied L-AP-4, and the effect of this agonist is illustrated in E-H.E, Evoked EPSCS; F, sEPSC amplitude; G, SEPSC frequency before, during, and after L-AP-4 application for one representative neuron. $H$, Representative sEPSCS. E, Inset, Representative evoked EPSCs. In each case, the bar graphs to the right show average data from all experiments of this type. $a, i, b, i, c$, iii, Before, during, and after agonist application, respectively.

the majority of excitatory nerve terminals that express functional P2X channels do so via a complex containing P2X2 subunits.

\section{P2X2 subunits are also sufficient for ATP-evoked}

\section{synaptic facilitation}

Because P2X2 subunit-containing channels are the predominant targets for ATP in synapses onto SR interneurons, the next set of experiments tested for the ability to measure ATP $\gamma \mathrm{S}$-mediated increases in mEPSCs from pyramidal cells by adding extra P2X2 channels. Recent work with GABA transporter type 1-green fluorescent protein (GFP)-labeled interneurons shows that the majority $(80-90 \%)$ of hippocampal neurons in culture are pyramidal (Chiu et al., 2002). In accord with our previous work (Khakh et al., 2001), we found no evidence for modulation of mEPSC frequency $(n=4$; Fig. $7 B)$ in wild-type hippocampal neurons in culture, from $0.2 \pm 0.1$ in control to $0.1 \pm 0.1 \mathrm{~Hz}$ during ATP $\gamma \mathrm{S}$. We next expressed P2X2-GFP fusion proteins in hippocampal neurons with Sindbis viruses (Fig. 7A), which results in approximately threefold to sixfold channel overexpression (Khakh et al., 2001). One day after infection, we recorded from nonfluorescing neurons and puffed ATP $\gamma S$ onto the surrounding fluorescent neurites (Fig. 7A). In all such cases, ATP $\gamma \mathrm{S}$ puffs reliably increased the frequency but not the amplitude of mEPSCs from $0.6 \pm 0.3$ to $12.2 \pm 2.6 \mathrm{~Hz}(n=5$; Fig. $7 C, D)$. Whereas the P2X2 null mice tell us that P2X2 channels are required at SR interneu- ron synapses, the present experiments provide complimentary support that overexpressed $\mathrm{P} 2 \mathrm{X} 2$ channels are also sufficient to endow synapses onto CA1 neurons with nerve terminal P2Xmediated modulation.

\section{ATP $\gamma \mathrm{S}$ does not trigger network activity}

Cholinergic $(\mathrm{CCh})$ induction of theta and gamma oscillations in the hippocampus is a useful in vitro model for network activity in vivo that may arise from medial septum cholinergic input (Fisahn et al., 1998; Fellous and Sejnowski, 2000; Fisahn et al., 2002). We used CCh $(50-100 \mu \mathrm{M})$ and also muscarine $(10 \mu \mathrm{M})$ to induce oscillations, but in keeping with previous nomenclature, we refer to this as CCh-evoked activity. Under recording conditions similar to ours, CCh evokes hippocampal theta oscillations with occasional ripples of gamma (Fellous and Sejnowski, 2000; Tiesinga et al., 2001). Computational and experimental studies of CCh induced theta and gamma suggest that excitatory transmission onto interneurons is important (Fisahn et al., 1998; Fellous and Sejnowski, 2000; Traub et al., 2000; Tiesinga et al., 2001). Does $\mathrm{P} 2 \mathrm{X}$ channel activation evoke network activity within the CA3 region of the hippocampus? We found no evidence to indicate that ATP $\gamma \mathrm{S}(100 \mu \mathrm{M})$ evokes any change in the extracellular field potential $(n=6)$. However, in the same slices, CCh evoked a robust increase in extracellularly recorded field activity, which was completely blocked by TTX $(n=6)$. Figure $8 B$ shows power 
spectra for the representative traces in Figure $8 A$, and Figure $8 C$ summarizes findings for the whole data set. In agreement with the work of Fellous and Sejnowski (2000), we recorded a CCh-evoked oscillation with a fundamental frequency (Ff) of $12.4 \pm 0.4 \mathrm{~Hz}(n=6)$ (Tiesinga et al., 2001). These experiments suggest that increasing the frequency of sEPSCs by $\sim 700 \%$ in $\sim 60 \%$ of stratum radiatum interneurons (Figs. 1-3) is insufficient to trigger a detectable network activity as measured in CA3.

\section{P2X channels enhance interneuron synaptic transmission during network activity}

How are presynaptic P2X channels onto interneuron synapses activated physiologically? ATP released during spiking (Wieraszko et al., 1989; Mori et al., 2001; Pankratov et al., 2002) may activate presynaptic P2X channels at interneuron synapses. To test for this, we induced neuronal firing at physiological frequencies by inducing oscillations with CCh (Fig. 8). sEPSCs onto interneurons increased in frequency during oscillations by $\sim 1500 \%$ (Fig. $9 A-C$ ), and, reminiscent of the ability of TTX to block oscillations (Fig. $8 C$ ), the increase in sEPSC frequency measured from interneurons was only $225 \pm 55 \%(n=8)$ of control in the presence of TTX. The major component of the increase in sEPSCs is likely because of CCh-evoked oscillations. We asked whether endogenous ATP release contributed to this enhanced synaptic transmission by activating presynaptic facilitatory P2X channels that are functional at these synapses (Fig. 4). Because PPADS has a slow on rate ( $\sim 10 \mathrm{~min})$, the simplest way to test for this was to compare the effect of CCh on sEPSCs from control slices and those pretreated with $30 \mu \mathrm{M}$ PPADS to block P2X channels. In control slices, application of CCh resulted in an $1820 \pm$ $480 \%(n=23)$ increase in sEPSC frequency onto interneurons (Fig. 9A,C), but in PPADS-treated slices, this was significantly reduced to $422 \pm 73 \%$ (Fig. 9B, $C ; n=21 ; p<0.05$ compared with control slices), implying that the PPADS-sensitive P2X component constitutes $\sim 77 \%$ of the total response. There were no significant differences in the amplitude of CCh-evoked sEPSCs when comparing across the whole data set for control slices and those pretreated with PPADS $(139 \pm 12 \% ; n=23 ; 129 \pm 8 \%$ of control; $n=21$; Fig. 9 C). In a specific set of experiments, we also examined the effect of blocking P2X channels in real time on CCh-evoked sEPSC facilitation in interneurons in which this was constant for a baseline period of at least 5-10 min (5 of 19 neurons). Representative traces are shown in Figure 9D, and the effect of PPADS is manifest as a decrease in the area of sEPSCs during CCh. CCh increased sEPSC frequency by $1461 \pm 174 \%$, but in the same neurons in the presence of PPADS, this was reduced to $310 \pm 137 \%$ of control (Fig. 9D, bar graphs; $n=4$ ). From these experiments, we suggest that the predominant effect of PPADS is to reduce the CCh oscillation-evoked increase in sEPSC frequency onto interneurons. We interpret this to indicate that CCh oscillations release ATP, which acts presynaptically to facilitate transmitter release. Consistent with this, we measured increases in ATP-dependent bioluminescence from the firefly luciferase reaction in response to CCh application to brain slices, demonstrating that ATP is released into the extra-
A

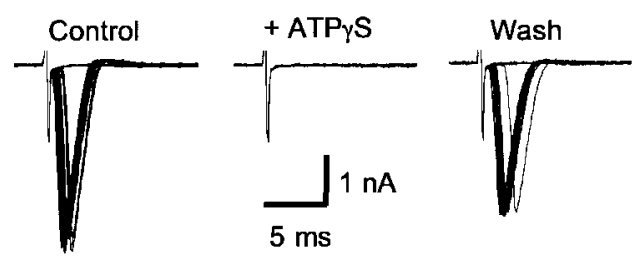

B

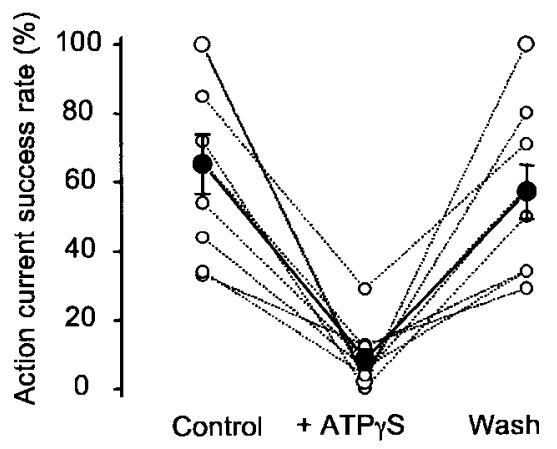

Figure 5. The success rate of antidromic action currents is decreased during ATP $\gamma S$ application. $A$, Representative action currents before, during, and after ATP $\gamma$ S application. B, Data from experiments similar to those shown in $A$. The filled symbols are the average, and the open symbols are the individual neurons. Action currents were evoked with a glass monopolar electrode filled with aCSF and placed in the Schaffer collaterals. We used a pulse width of 10-100 $\mu$ sec and varied the stimulus strength to obtain $\sim 50 \%$ failures in antidromic action currents. The stimulating electrode had to be repositioned several times before an antidromic action current could be recorded in CA3 neurons.

cellular space during neuronal oscillations at approximate theta frequencies (Table 2). CCh-evoked ATP release was significantly reduced when action potentials were blocked by TTX (Table 2).

Consistent with the lack of presynaptic P2X channels at pyrami- 

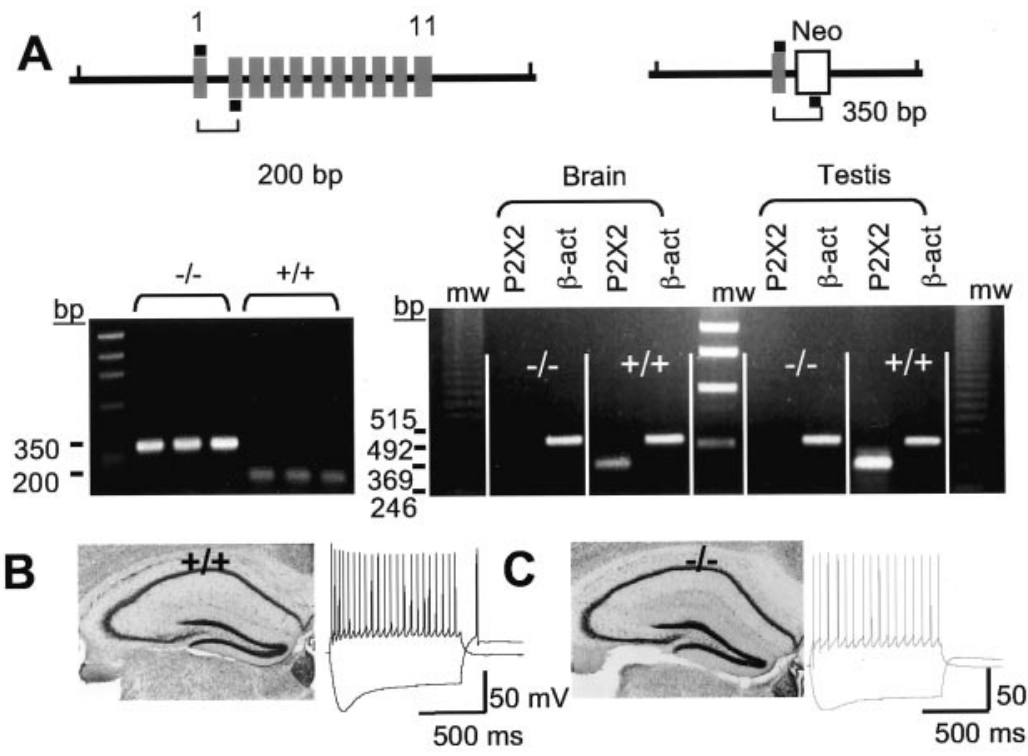

B
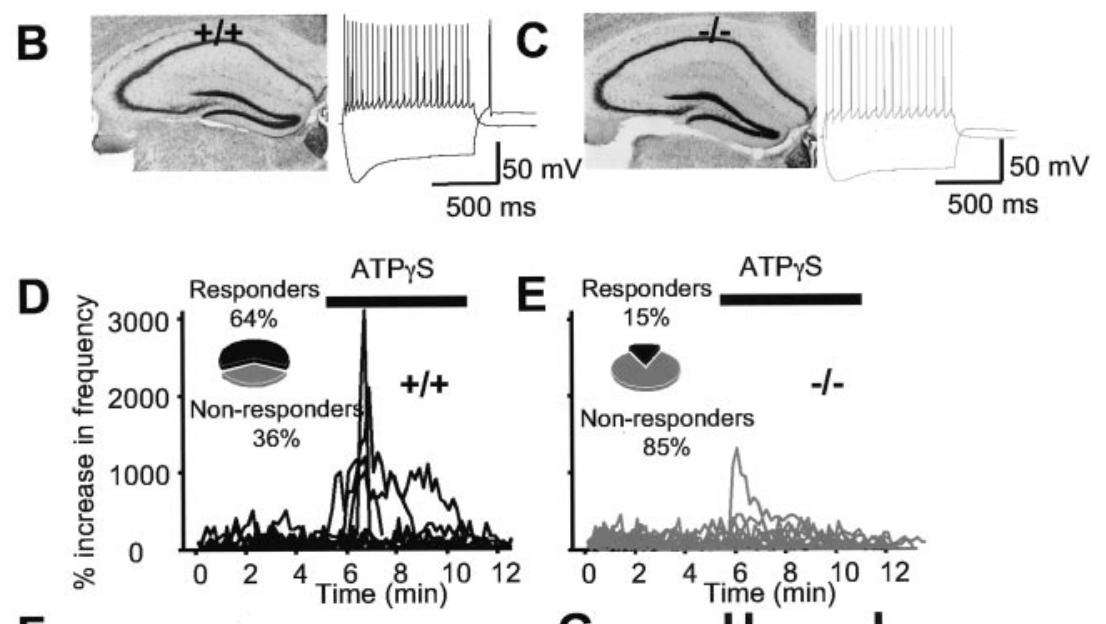

$\mathbf{F}$
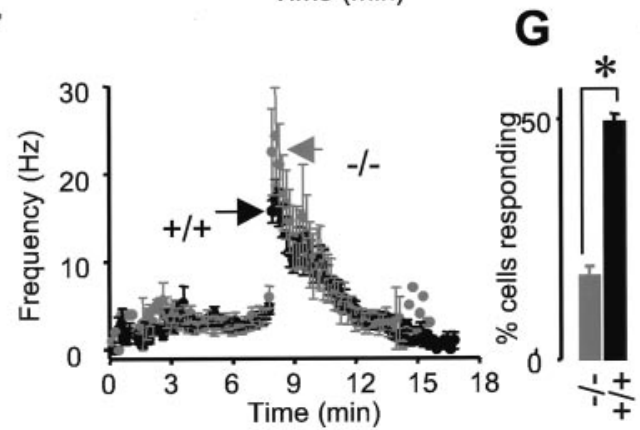

$\mathrm{H}$

Figure 6. $P 2 X 2$ channels are the targets for ATP at interneuron synapses. A, Top left, Diagrammatic representation of the endogenous mouse P2X2 (mP2X2) locus with 11 exons. Top right, Representation of the targeted locus with exons 2-11 deleted and replaced with Neo. In both diagrams, the black bars indicate the approximate positions of the primers used for PCR analysis of tail genomic DNA, as shown in the gel to the left. Both the PCR and Southern blot (results not shown) approaches show that the $\mathrm{mP2X} 2$ gene is disrupted with Neo, but because we ran the PCR screen with all three primers, this approach additionally shows that exons downstream of exon 1 are deleted because no wild-type band was detected (left gel). Right gel, RT-PCR results from $\mathrm{P} 2 \times 2^{+1+}$ and $\mathrm{P} 2 \times 2^{-1-}$ mice with mRNA harvested from brain and testis. There was $\mathrm{P} 2 \times 2 \mathrm{mRNA}$ in both brain and testis from $\mathrm{P} 22^{+1+}$ mice but not from $\mathrm{P} 2 \mathrm{X} 2^{-1-}$ mice. mRNA for $\beta$-actin $(\beta$-act) was present in both genotypes and tissues. mw, Molecular weight markers. $B, C$, Nissl staining in $\mathrm{P} 2 \times 2^{+1+}(B)$ and $\mathrm{P} 2 \mathrm{X}^{-1-}$ mice (C). The representative voltage waveforms show responses of interneurons to depolarizing and hyperpolarizing current injections. D, EPSC frequency against time for 11 interneurons recorded from a P2X2 ${ }^{+/+}$mouse; the inset indicates that $64 \%$ of neurons responded to P2X activation in this mouse. $E$, $\mathrm{mEPSC}$ frequency against time for 13 interneurons recorded from a P2X2 $2^{-1-}$ mouse; the inset indicates that only $15 \%$ of neurons responded to $P 2 X$ activation in this mouse. $F$, Summary of recordings for all neurons that responded to ATP $\gamma S$ from seven $\mathrm{P} 2 \times 2^{-1-}$ and seven $\mathrm{P} 2 \mathrm{X} 2^{+1+}$ mice. $G$, In the $\mathrm{P} 2 \mathrm{X}^{-1-}$ mice, the proportion of neurons that receive $\mathrm{P} 2 \mathrm{X}$-modulated synapses is significantly reduced $(p<0.05)$. $H$, I, Resting membrane potentials $(H)$ and membrane resistances $(I)$ for $P 2 X 2^{-I-}$ and $\mathrm{P} 2 \times 2^{+/+}$mice.

dal neuron synapses (Fig. 2), PPADS had no effect on the sEPSC frequency onto CA1 pyramidal neurons during CCh applications to evoke oscillations (Fig. 9E). Thus, CCh enhanced the sEPSC frequency onto pyramidal neurons to $1053 \pm 328 \%$ of control, and this did not change with PPADS (1153 $\pm 332 \%$; four of four neurons;

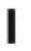

Fig. 9E). We also performed several control experiments to strengthen our findings with PPADS as an antagonist. PPADS was specific in that it did not block somatic glutamate responses $(n=4)$, glutamatergic evoked EPSCs $(n=5)$, or mEPSCs $(n=5)$; they were $-293 \pm 93,-142 \pm 36$, and $-15.8 \pm 1.8 \mathrm{pA}$ in control and $-326 \pm 103,-155 \pm 45$, and $-16.0 \pm 1.8 \mathrm{pA}$ in the presence of $30 \mu \mathrm{M}$ PPADS, respectively $(p>0.05$ for each comparison).

\section{A role for ATP in oscillations}

Because facilitatory presynaptic P2X channels are found at interneuron synapses and are likely activated during CCh-evoked oscillations, we sought to determine whether endogenous ATP contributes to either the frequency or power of CCh-induced oscillatory activity. First we ensured that PPADS did not block either muscarinic receptors or the excitability of CA3 neurons. In agreement with published work (Fisahn et al., 2002), CCh depolarized CA3 pyramidal neurons by $+8.9 \pm 1.7 \mathrm{mV}$ and increased spike frequency from $0.1 \pm 0.1$ to $5.8 \pm 1.2$ $\mathrm{Hz}(n=3)$. In the presence of PPADS, this was not markedly altered: the CCh-evoked depolarization was $+7.2 \pm 1.5 \mathrm{mV}$, and action potential firing increased from $0.1 \pm 0.1$ to $7.4 \pm 2.0 \mathrm{~Hz}(n=7)$. Moreover, the input-output curves for CA3 pyramidal neurons in the absence and presence of PPADS were superimposable $(n=5)$.

We next tested the effect of blocking P2X channels with PPADS on CCh oscillations. We determined the increase in power at the Ff (relative to the basal situation before $\mathrm{CCh}$ ) and compared it with the power at the Ff attributable to $\mathrm{CCh}$ in slices pretreated with PPADS ( $30 \mu \mathrm{M}$ for at least $20 \mathrm{~min}$ ). Thus, in control slices (no PPADS), CCh evoked oscillations with an Ff of $13.8 \pm 0.7 \mathrm{~Hz}(n=10)$. In slices treated with PPADS, CCh induced oscillations with an identical $\mathrm{Ff}$ at $13.4 \pm 0.7 \mathrm{~Hz}$ ( $n=16)$, but the power was reduced significantly by $\sim 80 \%$ at the Ff ( $p<0.05$; Fig. 10) in comparison with slices with no PPADS. These data suggest that ATP released during oscillations contributes to the overall power of cortical oscillations. A component of this may be ATP acting on P2X channels in nerve terminals or axons, as we have shown for exogenous and endogenous ATP at interneuron synapses.

\section{Discussion}

ATP-gated cationic P2X channels are numerous and widely expressed in the brain; therefore, it is important to understand their physiological and synaptic functions. Our data extend recent studies indicating that P2X channels are found presynaptically (MacDermott et al., 1999) by additionally 
making five further advances. First, we provide evidence for the presence and function of a molecularly defined P2X channel in a brain synapse. Second, we demonstrate that $\mathrm{P} 2 \mathrm{X} 2$ subunitcontaining channels are functional close to nerve terminals and in axons but surprisingly not in somata of CA3 neurons. Third, we provide evidence to suggest that the identity of the postsynaptic target determines modulation by presynaptic $\mathrm{P} 2 \mathrm{X} 2$-containing channels within the CA1 region of the hippocampus. Fourth, we show that endogenous ATP activates presynaptic P2X channels during network activity. Fifth, we provide evidence in favor of a novel form of ATP-dependent presynaptic facilitation for interneurons during oscillations.

\section{ATP signaling}

The finding that $\mathrm{P} 2 \mathrm{X}$ channels are not functionally expressed in CA3 neuron somata was a surprise because P2X2, P2X4, and P2X6 immunostaining is present in these neurons (Kanjhan et al., 1999; Rubio and Soto, 2001). Recent studies show ATP-evoked currents in these neurons (Mori et al., 2001). The clearest difference between these studies and ours is that we used freshly isolated mouse slices, whereas the ATP-evoked somatic currents are from rat cultured slices (Mori et al., 2001). It seems feasible that once isolated, neurons may either retract their processes and therefore display aberrant somatic ATPevoked currents or otherwise upregulate somatic P2X expression, as has been suggested for sensory neurons (North, 2002). We interpret our findings to indicate that P2X channels are not functionally expressed in intact CA3 neuron somata but are predominantly functional in the axons, and a specific set of nerve terminals, that emanate from these neurons.

Decisive evidence for the role of distinct P2X channels in brain synapses has been lacking because the discriminating differences between P2X channels are fewer than the possible number of P2X channel assemblages (North, 2002). We have circumvented these limitations to some extent by using electrophysiology and P2X2 subunit null mice. Our data show that $>80 \%$ of the ATP-evoked presynaptic response was blocked by PPADS (30 $\mu \mathrm{M})$, which blocks P2X2 but not P2X4 channels (North, 2002). In comparison, there is a residual response in $\mathrm{P} 2 \mathrm{X} 2$ null mice that amounts to $\sim 40 \%$ of the total population that respond to ATP $\gamma \mathrm{S}$ in wildtype mice. The absolute magnitude of the response in these $40 \%$ of cells is similar to the component mediated by the total receptor population in the wild-type mice, suggesting that the $40 \%$ residual component may represent upregulation of an unknown P2X channel, or that expression of P2X2 and the unknown channel type does not overlap in nerve terminals. Overall, these findings imply that a presently unidentified channel, resistant to PPADS, mediates at most $20 \%$ of the response. This component may be
B. wt D
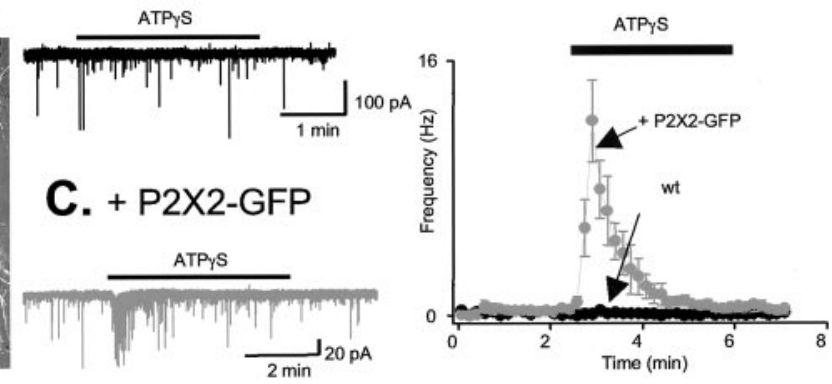

Figure 7. P2X2 channel overexpression endows cultured hippocampal neurons with ATP-mediated facilitation of mEPSCs. $A$, Top, Sindbis virus construct used to express P2X2-GFP under the control of a subgenomic promoter. Bottom, Photomicrograph showing a field of view of cultured hippocampal neurons, with the fluorescent GFP-expressing neurons shown in white. Note the 作 neurons in the presence of TTX. D, shows Average graph from six neurons from experiments like those illustrated in $C$ and four neurons from experiments like those shown in $B$.
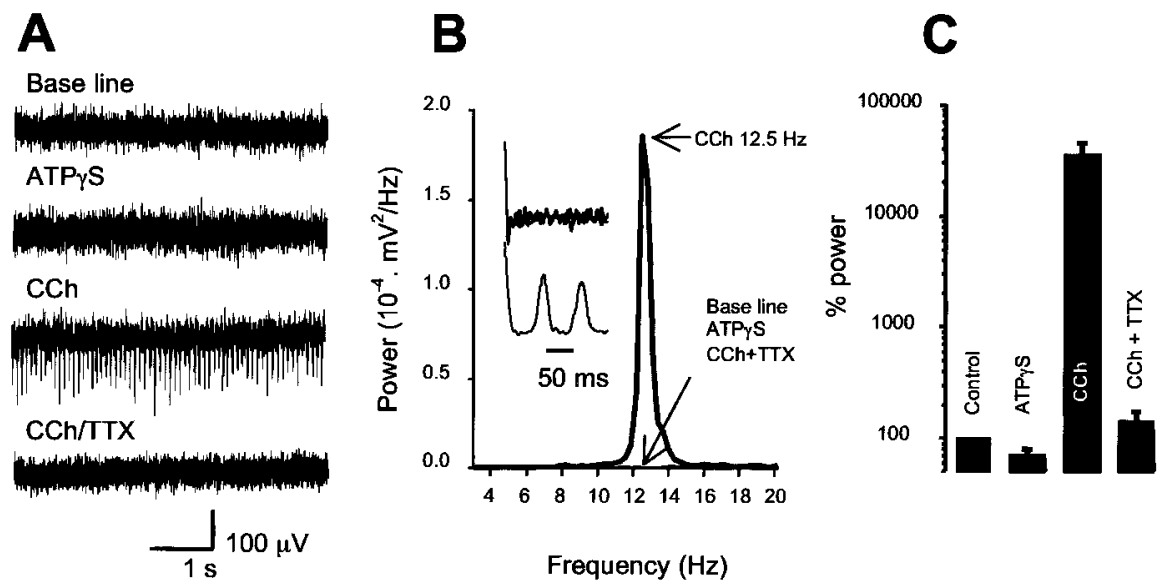

Figure 8. ATP $\gamma S$ does not trigger CA3 network activity, whereas CCh does. $A$, Representative voltage traces from extracellular field recordings in basal conditions (with no drugs added) in the presence of ATP $\gamma S(100 \mu \mathrm{m}), \mathrm{CCh}(50-100 \mu \mathrm{m})$, and also CCh plus TTX (1 $\mu \mathrm{M})$. Only CCh caused oscillatory activity. B, Power spectra of 20 sec traces from the representative examples shown in $A$. There is a single fundamental frequency peak at $12.5 \mathrm{~Hz}$ in the presence of $\mathrm{CCh}$. Inset, Autocorrelograms (with positive lags shown). C, Summary of all experiments like those illustrated in $A$ and $B$.

upregulated in $\sim 40 \%$ of the neurons that have near normal peak responses in the $\mathrm{P} 2 \mathrm{X} 2^{-1-}$ mice and could conceivably represent another P2X channel, including P2X7 (Deuchars et al., 2001; Sperlagh et al., 2002). Nonetheless, the predominant target for ATP at excitatory synapses onto interneurons is a homomeric or heteromeric channel comprising P2X2. Moreover, the facilitatory effect of ATP $\gamma S$ on interneuron EPSCs was completely blocked by removal of extracellular $\mathrm{Ca}^{2+}$ but persisted in the presence of TTX and $\mathrm{Cd}^{2+}$, indicating that ATP $\gamma S$ likely gates a $\mathrm{Ca}^{2+}$-permeable ion channel in nerve terminals (MacDermott et al., 1999). P2X2 channels are known to have significant $\mathrm{Ca}^{2+}$ permeability on the basis of reversal potentials (North, 2002).

The evidence that P2X channels are functional in Schaffer collateral axons (Kanjhan et al., 1999) as well as in nerve terminals is fourfold. First, we measured increases in action potentialdependent sEPSC frequency while recording from the postsynaptic targets of CA3 axons. Second, we measured increases in mEPSC frequency with ATP $\gamma S$ application. Third, we placed a stimulating electrode in the Schaffer collaterals and measured 

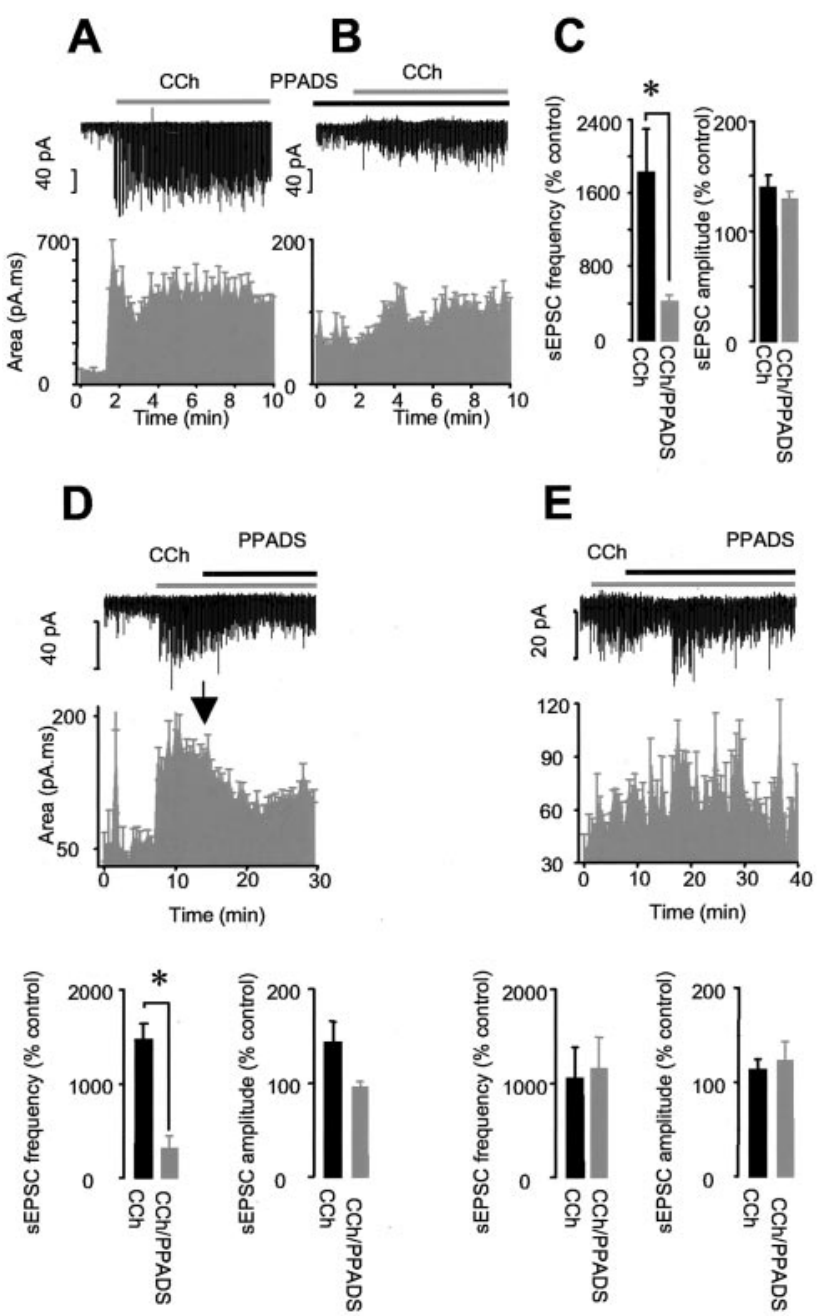

Figure 9. ATP contributes to the facilitation of interneuron synapses that occurs during oscillations. $A$, Top plot, Representative current trace from an interneuron before and during the induction of CCh oscillations. Bottom plot, EPSC area (10 sec bins) over time for this neuron. $B$, Top plot, Representative current trace from an interneuron before and during the induction of CCh oscillations in the continued presence of PPADS (30 $\mu \mathrm{m})$. Bottom plot, EPSC area (10 sec bins) over time for this neuron. C, Summary bar graphs for experiments like those illustrated in $A$ and $B$. D, Top plot, Current trace from an interneuron before and during the induction of oscillations by CCh. Middle plot, Effect of PPADS by plotting the EPSC area (10 sec bins) over time. The bottom graphs summarize the findings from all such interneurons. E, Top plot, Current trace from a CA1 pyramidal before and during the induction of oscillations by CCh. As illustrated in the middle plot, there was little change in EPSC areas during application of PPADS. The effect of CCh was less pronounced in pyramidal neurons as compared to interneurons. The bottom graphs summarize findings from all such experiments. In $A, B, D$, and $E$, we plotted area versus time because during $C C h$ applications, we recorded increases in SEPSC frequency and a greater number of larger-amplitude sEPSCS (see original traces in $A, B, C, E$ ). The large-amplitude sEPSCS in the presence of CCh probably arise because $C A 3$ neurons fire action potentials during oscillations and cause release of transmitter synchronously from multiple release sites onto interneurons. PPADS clearly reduced the frequency of CCh-evoked sEPSCs ( $D$, left graph), but although there was a trend for the sEPSCS to decrease in amplitude in the presence of PPADS, this did not reach significance ( $D$, right graph).

evoked ESPCs from interneurons. During ATP $\gamma S$ application, evoked EPSCs decreased in peak amplitude, with a time course matching the increase in frequency of sEPSCs recorded simultaneously (Fig. 3). Fourth, we measured a manifest increase in the failure of antidromic action currents recorded from CA3 pyramidal neurons and evoked by stimulation in the Schaffer collaterals during ATP $\gamma S$ applications. Certain aspects of our findings are reminiscent of the neuromuscular junction, nucleus tractus soli- tarius, and dorsal horn (Fu and Poo, 1991; Kato and Shigetomi, 2001; Nakatsuka and Gu, 2001) but constitute the first such findings for ATP effects on interneuron synaptic transmission.

\section{Facilitation by ATP during network activity}

Within the CA1 region, stratum radiatum interneurons receive their predominant excitatory input from Schaffer collaterals. By virtue of their precise projection patterns, interneurons set a time window for when output CA1 neurons cannot spike and additionally regulate dendritic $\mathrm{Ca}^{2+}$ entry (McBain and Fisahn, 2001). The present data indicate that exogenous ATP $\gamma S$ cannot trigger network oscillations, but that endogenous ATP is a presynaptic modulator of neurotransmission at stratum radiatum interneuron synapses during firing at approximately theta frequencies. The high specificity of luciferase for ATP provides evidence for ATP release from brain slices during CCh applications. Previous studies have demonstrated ATP release into the extracellular buffer as a result of Schaffer collateral stimulation (Wieraszko et al., 1989). Thus, the most obvious sources of ATP are the CA3 neuron terminals themselves, but alternative sources such as astrocytes (Newman, 2001) cannot be dismissed at present. Our experiments show that the facilitation of excitatory synaptic transmission onto interneurons that occurs during oscillations is partly mediated by endogenously released ATP activating P2X channels. Our analysis of CCh-evoked oscillations in hippocampal slices favors the idea that endogenous ATP may contribute to overall oscillation power, but further work is needed before a complete understanding can emerge, for instance, to understand the role of ATP at GABAergic synapses and at gap junctions (McBain and Fisahn, 2001).

An unexpected finding from our work is that presynaptic P2X2-mediated modulation appears specific for interneurons and is undetectable at synapses onto CA1 pyramidal neurons. Elegant studies have described target synapse specificity with respect to synaptic parameters such as short-term depression, potentiation, and plasticity (for review, see Toth and McBain, 2000; Atwood and Karunanithi, 2002), but with the exception of the metabotropic glutamate receptors (Shigemoto et al., 1996), the presynaptic proteins responsible have not been identified. Interestingly, previous immunogold studies failed to find P2X2 channels in nerve terminals on CA1 pyramidal neurons (Rubio and Soto, 2001), whereas there was expression in the Schaffer collateral bundle at the light microscope level (Kanjhan et al., 1999; Rubio and Soto, 2001). Our data offer a new interpretation of these apparently conflicting studies and sharpen our view of P2X2-mediated signaling in the hippocampus: P2X2 channels are in Schaffer collaterals, but expression in nerve terminals may be determined by the identity of the postsynaptic target. Functional exclusion of $\mathrm{P} 2 \mathrm{X} 2$ channels from nerve terminals onto pyramidal neurons may be a saturable process because approximately threefold to sixfold P2X2 channel overexpression overcomes it. A restrictive barrier, perhaps associated with the cytoskeleton, regulates movement of membrane proteins into hippocampal neuron axons (Winckler et al., 1999). A similar or more selective barrier at axonal branches, or at individual nerve terminals, would be a simple way to ensure target synapse specificity of P2X2 channels, and some P2X channels may indeed interact with the cytoskeleton (Parker, 1998; Kim et al., 2001). As far as we know, the present study, demonstrating preferential expression of functional $\mathrm{P} 2 \mathrm{X}$ channels not in CA3 pyramidal neuron somata but in their axons and a specific set of nerve terminals that emanate from these, is the first such example for a brain neuron. A recent study on AMPA channels in sensory neurons (Lee et al., 2002) 
Table 2. ATP release from brain slices

\begin{tabular}{lllll}
\hline Value & Control period $(5 \mathrm{~min})$ & $30 \mathrm{~mm} \mathrm{KCl}(5 \mathrm{~min})$ & $100 \mu \mathrm{m}$ muscarine $(5 \mathrm{~min})$ & TTX/100 $\mu \mathrm{m} \mathrm{muscarine}(5 \mathrm{~min})$ \\
\hline ATP bioluminescence (\% initial) & $100.3 \pm 2.0$ & $162.5 \pm 17.0^{*}$ & $143.2 \pm 10.4^{*}$ & $112.6 \pm 6.1$ \\
$n$ & 8 & 6 & 5 & 7 \\
\hline
\end{tabular}

There was negligible increase in the ATP-dependent bioluminescence signal over successive 5 min periods, whereas KCl caused a profound increase. Similarly, induction of spiking with muscarine significantly increased the ATP-dependent bioluminescence signal, and blocking action potential conduction abolished this effect. We chose a 5 min window to measure ATP release because the electrophysiological studies in brain slices (Fig. 9) show that the muscarine effect peaks in $\sim 5$ min.

* Values were significantly different from control values as determined by an unpaired $t$ test at $p<0.05$.

and the present study prepare us for the possibility that preferential expression near nerve terminals may be a physiologically important attribute of neurotransmitter-gated ion channels.

\section{References}

Atwood HL, Karunanithi S (2002) Diversification of synaptic strength: presynaptic elements. Nat Rev Neurosci 3:497-516.

Burnstock G (1972) Purinergic nerves. Pharmacol Rev 24:509-581.

Buzsaki G (2002) Theta oscillations in the hippocampus. Neuron 33:325-340.

Chiu CS, Jensen K, Sokolova I, Wang D, Li M, Deshpande P, Davidson N, Mody I, Quick MW, Quake SR, Lester HA (2002) Number, density, and surface/cytoplasmic distribution of GABA transporters at presynaptic structures of knock-in mice carrying GABA transporter subtype 1-green fluorescent protein fusions. J Neurosci 22:10251-10266.

Cockayne DA, Dunn PM, Burnstock G, Ford APD (2002) Generation and electrophysiological characterization of $\mathrm{P} 2 \mathrm{X}_{2}$ and $\mathrm{P} 2 \mathrm{X}_{3}$ knockout $(\mathrm{KO})$ mice. Soc Neurosci Abstr 28:52.12.

Collo G, North RA, Kawashima E, Merlo-Pich E, Neidhart S, Surprenant A, Buell G (1996) Cloning of $\mathrm{P} 2 \mathrm{X}_{5}$ and $\mathrm{P} 2 \mathrm{X}_{6}$ receptors and the distribution and properties of an extended family of ATP-gated ion channels. J Neurosci 16:2495-2507.

Deuchars SA, Atkinson L, Brooke RE, Musa H, Milligan CJ, Batten TF, Buckley NJ, Parson SH, Deuchars J (2001) Neuronal P2X7 receptors are targeted to presynaptic terminals in the central and peripheral nervous systems. J Neurosci 21:7143-7152.

Fellous JM, Sejnowski TJ (2000) Cholinergic induction of oscillations in the hippocampal slice in the slow $(0.5-2 \mathrm{~Hz})$, theta $(5-12 \mathrm{~Hz})$, and gamma (35-70 Hz) bands. Hippocampus 10:187-197.

Fisahn A, Pike FG, Buhl EH, Paulsen O (1998) Cholinergic induction of network oscillations at $40 \mathrm{~Hz}$ in the hippocampus in vitro. Nature 394:186-189.

Fisahn A, Yamada M, Duttaroy A, Gan JW, Deng CX, McBain CJ, Wess J (2002) Muscarinic induction of hippocampal gamma oscillations requires coupling of the M1 receptor to two mixed cation currents. Neuron 33:615-624.

Frazier CJ, Rollins YD, Breese CR, Leonard S, Freedman R, Dunwiddie TV (1998) Acetylcholine activates an $\alpha$-bungarotoxin-sensitive nicotinic current in rat hippocampal interneurons, but not pyramidal cells. J Neurosci 18:1187-1195.

Freund TF, Buzsaki G (1996) Interneurons of the hippocampus. Hippocampus 6:347-470.

Fu WM, Poo MM (1991) ATP potentiates spontaneous transmitter release at developing neuromuscular synapses. Neuron 6:837-843.

Gulyas AI, Megias M, Emri Z, Freund TF (1999) Total number and ratio of excitatory and inhibitory synapses converging onto single interneurons of different types in the CA1 area of the rat hippocampus. J Neurosci 19:10082-10097.

Hinkle PE, McCarty RE (1978) How cells make ATP. Sci Am 238:104-123.

Hogan B, Beddington R, Constantini F, Lacy E (1994) Manipulating the mouse embryo: a laboratory manual. Cold Spring Harbor, NY: Cold Spring Harbor Laboratory.

Kanjhan R, Housley GD, Burton LD, Christie DL, Kippenberger A, Thorne

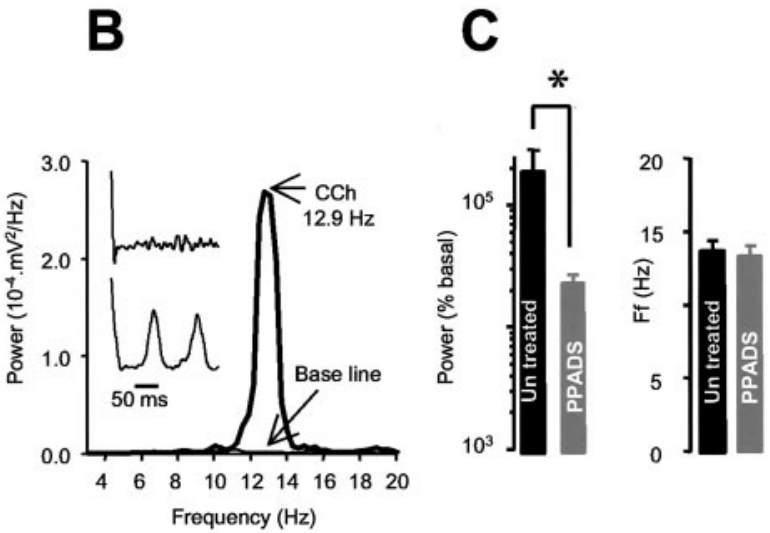

ower of CCh oscillations. A, Representative field potential traces and power spectra for $\mathrm{CCh}$ oscillations in a slice pretreated with PPADS. Inset, Autocorrelograms (with positive lags shown). B, Summary of experiments such as those illustrated in $A$ comparing the $C(h$-induced oscillation frequency and power for control slices and those treated with PPADS. The recording electrode was positioned in CA3. C, Summary of all experiments like those illustrated in $A$ and $B$.

PR, Luo L, Ryan AF (1999) Distribution of the P2X2 receptor subunit of the ATP-gated ion channels in the rat central nervous system. J Comp Neurol 407:11-32.

Kato F, Shigetomi E (2001) Distinct modulation of evoked and spontaneous EPSCs by purinoceptors in the nucleus tractus solitarii of the rat. J Physiol (Lond) 530:469-486.

Khakh BS (2001) Molecular physiology of P2X receptors and ATP signalling at synapses. Nat Rev Neurosci 2:165-174.

Khakh BS, Henderson G (1998) ATP receptor-mediated enhancement of fast excitatory neurotransmitter release in the brain. Mol Pharmacol 54:372-378.

Khakh BS, Humphrey PP, Henderson G (1997) ATP-gated cation channels (P2X purinoceptors) in trigeminal mesencephalic nucleus neurons of the rat. J Physiol (Lond) 498:709-715.

Khakh BS, Smith WB, Chiu CS, Ju D, Davidson N, Lester HA (2001) Activation-dependent changes in receptor distribution and dendritic morphology in hippocampal neurons expressing P2X2-green fluorescent protein receptors. Proc Natl Acad Sci USA 98:5288-5293.

Kidd EJ, Grahames CB, Simon J, Michel AD, Barnard EA, Humphrey PP (1995) Localization of P2X purinoceptor transcripts in the rat nervous system. Mol Pharmacol 48:569-573.

Kim M, Jiang LH, Wilson HL, North RA, Surprenant A (2001) Proteomic and functional evidence for a P2X7 receptor signalling complex. EMBO J 20:6347-6358.

Lee CJ, Bardoni R, Tong C-K, Engelman S, Joseph DJ, Magherini PC, MacDermott AB (2002) Functional expression of AMPA receptors on central terminals of rat dorsal root ganglion neurons and presynaptic inhibition of glutamate release. Neuron 35:135-146.

MacDermott AB, Role LW, Siegelbaum SA (1999) Presynaptic ionotropic receptors and the control of transmitter release. Annu Rev Neurosci 22:443-485.

McBain CJ, Fisahn A (2001) Interneurons unbound. Nat Rev Neurosci 2:11-23.

Miles R, Toth K, Gulyas AI, Hajos N, Freund TF (1996) Differences between somatic and dendritic inhibition in the hippocampus. Neuron $16: 815-823$.

Mori M, Heuss C, Gahwiler BH, Gerber U (2001) Fast synaptic transmission 
mediated by $\mathrm{P} 2 \mathrm{X}$ receptors in CA3 pyramidal cells of rat hippocampal slice cultures. J Physiol (Lond) 535:115-123.

Nakatsuka T, Gu JG (2001) ATP P2X receptor-mediated enhancement of glutamate release and evoked EPSCs in dorsal horn neurons of the rat spinal cord. J Neurosci 21:6522-6531.

Newman EA (2001) Propagation of intercellular calcium waves in retinal astrocytes and Muller cells. J Neurosci 21:2215-2223.

North RA (2002) Molecular physiology of P2X receptors. Physiol Rev 82:1013-1067.

Pankratov YV, Lalo UV, Krishtal OA (2002) Role for P2X receptors in longterm potentiation. J Neurosci 22:8363-8369.

Parker KE (1998) Modulation of ATP-gated non-selective cation channel (P2X1 receptor) activation and desensitization by the actin cytoskeleton. J Physiol (Lond) 510:19-25.

Rubio ME, Soto F (2001) Distinct localisation of P2X receptors at excitatory postsynaptic specializations. J Neurosci 21:641-653.

Scanziani M, Gahwiler BH, Charpak S (1998) Target cell-specific modulation of transmitter release at terminals from a single axon. Proc Natl Acad Sci USA 95:12004-12009.

Semyanov A, Kullmann DM (2001) Kainate receptor-dependent axonal depolarization and action potential initiation in interneurons. Nat Neurosci 4:718-723.

Shigemoto R, Kulik A, Roberts JD, Ohishi H, Nusser Z, Kaneko T, Somogyi P (1996) Target-cell-specific concentration of a metabotropic glutamate receptor in the presynaptic active zone. Nature 381:523-525.
Sperlagh B, Kofalvi A, Deuchars J, Atkinson L, Milligan CJ, Buckley NJ, Vizi ES (2002) Involvement of P2X7 receptors in the regulation of neurotransmitter release in the rat hippocampus. J Neurochem 81:1196-1211.

Tiesinga PH, Fellous JM, Jose JV, Sejnowski TJ (2001) Computational model of carbachol-induced delta, theta, and gamma oscillations in the hippocampus. Hippocampus 11:251-274.

Torres G, Egan T, Voigt M (1999) Hetero-oligomeric assembly of P2X receptor subunits: specificities exist with regard to possible partners. J Biol Chem 274:6653-6659.

Toth K, McBain CJ (2000) Target-specific expression of pre- and postsynaptic mechanisms. J Physiol (Lond) 525:41-51.

Traub RD, Bibbig A, Fisahn A, LeBeau FE, Whittington MA, Buhl EH (2000) A model of gamma-frequency network oscillations induced in the rat CA3 region by carbachol in vitro. Eur J Neurosci 12:4093-4106.

Wieraszko A, Goldsmith G, Seyfried TN (1989) Stimulation-dependent release of adenosine triphosphate from hippocampal slices. Brain Res 485:244-250

Winckler B, Forscher P, Mellman I (1999) A diffusion barrier maintains distribution of membrane proteins in polarized neurons. Nature 397:698-701.

Zimmermann H (1994) Signalling via ATP in the nervous system. Trends Neurosci 17:420-426.

Zimmermann H, Braun N (1996) Extracellular metabolism of nucleotides in the nervous system. J Auton Pharmacol 16:397-400. 